\title{
Childhood Poisoning, A Rising Epidemic in Developing Nations: Large Single Centre Study
}

\author{
Mishra S', Ramkumar TV², Biswas AK ${ }^{3}$ Panigrahi $\mathrm{S}^{4}$
}

\begin{abstract}
Introduction: Poisoning is a major problem in children. The aims of this study were to determine the pattern of poisoning in children along with seasonal incidence, duration of treatment and outcome in referral centre of eastern India. Materials and Methods: All the children admitted to paediatric ward of MKCG Medical college and hospital from $1^{\text {st }}$ April 2015 to $31^{\text {st }}$ march 2016 (1 year) with history or suspicion of poisoning and animal bites were included in the study. Brought dead patients and the children with side effects due to ingested drugs in prescribed amount were excluded from the study. Results: Total 530 cases were documented with highest incidence in rainy season. 1-6 years children were mostly vulnerable (42.6\%). Accidental mode was the major cause in small children and suicidal, in older. Animal bites and stings $(n=241)$ were the commonest followed by chemical poisonings. Kraits were commonest culprit in snake envenomation group. Alprazolam was most common drug causing drug overdose. Total numbers of death were 27. Major cause of death was organo- phosphorus poisoning (OP) and snakebite. Mean days of hospitalization was 2.5 days and death after hospitalization was 1.8 days. Conclusion: Most of the childhood poisonings were due to accidental cause. Animal bites were mostly due to snakes. Maximum numbers of deaths were due to OP poisoning. Watchful observation, clean and clear environment, understanding the problems of adolescence, friendly atmosphere in home can prevent most of the poisonings and animal bites in children.
\end{abstract}

Key words: accidental, childhood poisoning, envenomation, kerosene.

\section{Introduction}

A ccording to WHO data, in 2012 an estimated 193,460 people died worldwide from unintentional poisoning. Out of this $84 \%$ occurred in low- and middle-income countries. Whereas it has been estimated that about 5 million snake-bites occur each year, resulting in up to 2.5 million envenoming, at least 100,000 deaths and around three times as many amputations and other permanent disabilities. Out of them 41.9 poison exposures are seen in children younger than 6 years $/ 1000$ children $^{1}$. From WHO data it's apparent that
${ }^{1}$ Dr. Shubhankar Mishra, MBBS, MD, Senior Resident, Department of Paediatrics, Kalinga Institute of Medical Sciences (KIMS), Bubaneshwar, Odisha, India, ${ }^{2}$ TV Ramkumar, MBBS, MD, Assistant professor, Department of Paediatrics, Maharaja Krishna Chandra Gajapati (MKCG) Medical College, Berhampur, Odhisha, India, ${ }^{3} \mathrm{Dr}$. Ashok Kumar Biswas, Geriatric Public Health Specialist, The Department of Public Health, The Ministry of Health, Tabuk Region Office of the General Director of Health Affairs, Tabuk City, Kingdom of Saudi Arabia, ${ }^{4} \mathrm{Dr}$. Sambedana Panigrahi, MBBS, Junior Resident, Department of Paediatrics, Kalinga Institute of Medical Science, Bhubaneswar, Odisha, India.

\section{Address for correspondence}

Dr. Shubhankar Mishra, MD, Senior Resident Department of Paediatrics,

Kalinga Institute of Medical Sciences,

Bubaneshwar, Odisha, India.

Tel No;

E-mail: dr.subham.scb@gmail.com

Acknowledgements: None.

Funding: Nil

Conflict of Interest: None

Permission from IRB: The study was approved by IRB of MKCG Medical College, Berhampur, Odisha

\section{How to cite}

Mishra S, Ramkumar TV, Biswas AK, Panigrahi S. Childhood Poisoning, A Rising Epidemic in Developing Nations: Large Single Centre Study. J Nepal Paediatr Soc 2017;37(2):117121.

doi: http://dx.doi.org/10.3126/jnps.v37i2.16843

This work is licensed under a Creative Commons Attribution 3.0 License.

(c) (i) 
poisoning is a major problem in children all over the world ${ }^{2}$. The pattern of poisoning has been changing with new hazards constantly appearing due to introduction of new drugs and chemicals. Childhood poisoning is usually accidental, but suicidal causes are also common in older children due to stressful life. The trends and patterns for paediatric poisoning in developing countries like India are same as it was decades ago, despite the rapid socioeconomic development ${ }^{2,3}$. In sharp contrast to developing countries, where majority of poisonings are due to common non-toxic household products, most of our patients require hospitalization because of severe symptoms related to dangerous nature of toxins ingested ${ }^{2}$. Cautious parenthood can save many children and adolescents from acute poisoning. There is dearth of large studies to quantify the problem and its solution. The aim of this study was to determine the pattern of poisoning in children along with seasonal incidence, duration of treatment and outcome in department of paediatrics, MKCG Medical College, Odisha, a large referral centre of eastern India.

\section{Materials and Methods}

The present study was a prospective observational study conducted over a period of 1 year ( $1^{\text {st }} A$ pril $2015-31^{\text {st }}$ march 2016) in department of pediatrics, MKCG Medical College and hospital, Odisha, a tertiary teaching hospital in India. Children with history of consumption of poisons/ bites/ stings and/ with features of poisoning, without actual history were included in the study. The children with side effects due to ingested drugs in prescribed amount were excluded. All the cases were admitted in hospital for at least 24 hours. Following admission, the following data were recorded in a Performa.

a) Duration between consumption of poison and onset of symptoms,

b) Delay in hospitalization and duration of treatment were noted in all children in the study.
In case of bites and stings, details of type of bite, site of bite, time of bite were noted. Supportive care and specific treatments were given depending on the type of poison. The ethical clearance was obtained from the ethical committee of MKCG Medical College. Informed consent was signed from parents of the patients who were included in the study. Data were tabulated and statistically analyzed using graph pad version 5 .

\section{Results}

In present study incidence of cases of poisoning was $530(3.9 \%)$ out of 13,312 admitted children in one year. Male children constituted $68.3 \%$ of the total poisoning group $(n=530)$. The incidence of poisonings was highest in rainy season, i.e. months of August and September $(14.1 \%$ and $13.7 \%)$ respectively. The incidence of poisonings followed declining trend from September to March indicating lowest in the winter season, i.e. October to February. The highest numbers of poisoning cases were seen in 1-6 year age group consisting $42.6 \%$ of whole incidence followed by 10-14 year group which add $23.4 \%$ to the incidence. Accidental poisoning was most common cause in all the age groups where as homicidal cause of poisoning was seen in one patient. The incidence of accidental consumption of chemical was 268 out of 510 accidental poisonings (Table-1). There was very high incidence of kerosene poisoning in chemical poisoning group. Turpentine poisoning was the second common cause of chemical poisonings. Snake bite and scorpion stings were most common causes of animal bite. Alprazolam overdose was commonest cause of drug overdose (Table-2). Home prepared food poisoning was the most frequent cause of food poisoning. Maximum incidence of kerosene poisonings were seen from April to June (38.3\%) followed by July to September (33.8\%). The snakebite was highest in July to September (31.7\%). The incidence of scorpion sting was also highest from July to September. There were 27 deaths during the study period. The mean duration of stay was 2.5 days.

Table 1: Age specific incidence poisonings+ bites (intoxications \& envenomations)

\begin{tabular}{cccc}
\hline Age group & $\begin{array}{c}\text { Accidental } \\
\text { (poisonings+ bites) }\end{array}$ & Suicidal & Total (\%) $\mathbf{n = 5 3 0}$ \\
\hline $0-1$ year & $84(63+21)$ & 0 & $84(15.8 \%)$ \\
\hline $1-6$ year & $226(175+51)$ & 0 & $226(42.6 \%)$ \\
\hline $6-10$ year & $92(28+64)$ & 4 & $96(18.1 \%)$ \\
\hline $10-14$ year & $108(2+106)$ & 16 & $124(23.3 \%)$ \\
\hline
\end{tabular}


Table 2: Substance specific incidence

\begin{tabular}{|c|c|c|c|}
\hline Toxic agent & Types of agent & Number $(\%)(n=530)$ & Death $(\%)(n=27)$ \\
\hline \multirow{21}{*}{$\begin{array}{l}\text { Chemical } \\
\mathrm{N}=223\end{array}$} & Kerosene and petrol & $88(16.6 \%)$ & $2(7.4 \%)$ \\
\hline & Organophosphorus & $18(3.4 \%)$ & $4(14.8 \%)$ \\
\hline & Datura & $5(0.9 \%)$ & 0 \\
\hline & Turpentine & $47(8.8 \%)$ & 0 \\
\hline & Anti-Mosquito liquid & $9(1.6 \%)$ & 0 \\
\hline & Dettol & $2(0.3 \%)$ & 0 \\
\hline & Dye & $2(0.3 \%)$ & 0 \\
\hline & Mercury & $6(1 \%)$ & 0 \\
\hline & Toilet cleanser & $3(0.5 \%)$ & 0 \\
\hline & Rat killer & $11(2 \%)$ & 0 \\
\hline & Fenbalmate & $2(0.3 \%)$ & $1(3.7 \%)$ \\
\hline & Fungicide & $4(0.6 \%)$ & $1(3.7 \%)$ \\
\hline & Scabicide & $3(0.5 \%)$ & 0 \\
\hline & Bleach powder & $1(0.2 \%)$ & 0 \\
\hline & Cypermethrin & $3(0.5 \%)$ & $1(3.7 \%)$ \\
\hline & Castor oil & $1(0.2 \%)$ & 0 \\
\hline & $\begin{array}{l}\text { Laxman Rekha (Anti-cockroach } \\
\text { Chalk) }\end{array}$ & $3(0.5 \%)$ & 0 \\
\hline & Gun powder & $1(0.2 \%)$ & 0 \\
\hline & Camphor & $3(0.5 \%)$ & 0 \\
\hline & Oleander & $3(0.5 \%)$ & $1(3.7 \%)$ \\
\hline & Unknown & $8(1.2 \%)$ & $3(11.1 \%)$ \\
\hline \multirow{5}{*}{$\begin{array}{l}\text { Bites } \\
N=241\end{array}$} & Snake & $172(32.4 \%)$ & $9(33.3 \%)$ \\
\hline & Scorpion & $54(10.1 \%)$ & $1(3.7 \%)$ \\
\hline & Spider & $1(0.2 \%)$ & 0 \\
\hline & Insect & $2(0.3 \%)$ & 0 \\
\hline & Unknown & $12(2.2 \%)$ & $1(3.7 \%)$ \\
\hline \multirow{11}{*}{$\begin{array}{l}\text { Medication } \\
\mathrm{N}=29\end{array}$} & Alprazolam & $10(1.8 \%)$ & 0 \\
\hline & Anti-hypertensive & $4(0.6 \%)$ & 0 \\
\hline & Thyroxine & $3(0.5 \%)$ & 0 \\
\hline & Clonazepam & $1(0.2 \%)$ & 0 \\
\hline & Folvite & $1(0.2 \%)$ & 0 \\
\hline & Lorazepam & $3(0.5 \%)$ & 0 \\
\hline & Phenergan & $1(0.2 \%)$ & 0 \\
\hline & Anti-psychotic & $1(0.2 \%)$ & 0 \\
\hline & Iron tablet & $1(0.2 \%)$ & 0 \\
\hline & Phenytoin & $1(0.2 \%)$ & 0 \\
\hline & Unknown & $3(0.5 \%)$ & 0 \\
\hline \multirow{4}{*}{$\begin{array}{l}\text { Food } \\
\mathrm{N}=35\end{array}$} & Mushroom & $8(1.5 \%)$ & 0 \\
\hline & Botulinum & $4(0.6 \%)$ & $2(7.4 \%)$ \\
\hline & Home food & $19(3.5 \%)$ & 0 \\
\hline & Unknown & $2(0.3 \%)$ & $1(3.7 \%)$ \\
\hline Miscellaneous & & $4(0.6 \%)$ & 0 \\
\hline
\end{tabular}




\section{Discussion}

This was a single centre large study on paediatric poisonings. The overall incidence of pediatric poisoning in our study was $3.9 \%$ which is higher than previous studies done by Khadwagat but the incidence in our study falls within the range of incidence described by Khadgawat in Southern Asia (0.3\%-7.6\%) $)^{2,3,4}$. The high incidence in this study can be explained by regional variation.

High number of rural population depending upon cultivation and forest for livelihood dwell in this area of world which leads to more numbers of snakebites as many areas of eastern and north-eastern India and Nepal are endemic to varieties of snakes. Accidental intake was seen more commonly then suicidal and homicidal. Suicidal cause of poisoning was common in adolescent and pre adolescent age group. All the poisonings in less than 5 years age group were accidental. Children have greater risk than adults for unintentional poisoning, because they are smaller, have faster metabolic rates and are less able to physically handle toxic chemicals. In addition natural curiosity and their desire to put everything in their mouth increase their poisoning risks ${ }^{5}$. In all previous studies done in India, Bangladesh, Nepal and Srilanka reveal the similar statistics (very recent study by Rimal HS etal) $)^{5,6,7}$. Snakebite was more common in 6-10 and 10-14 age groups. Male children were highly affected in all the groups which go in hand with almost all previous studies ${ }^{8}$.

Snakebite was most common cause of death. Cobra was the snake attributed to increase in death toll. There was one death due to scorpion sting due to late presentation. Preserved meat was responsible for death of two brothers causing botulism. They presented very late to the emergency department after neurological complications.

Commonest chemical consumed as poison was kerosene followed by turpentine as seen in study of Ganga $\mathrm{N}$ etal ${ }^{8}$. The high incidence of kerosene and turpentine poisoning can be explained by careless attitude of parents who keep the needful chemicals in the reach of children. Another cause is storage of kerosene and turpentine in beverage bottles. Small children can't differentiate easily and drink kerosene thinking it to be water due to its transparent and translucent features. The higher incidence of kerosene poisonings are seen in the time of disasters due to long power cuts when people need more use of kerosene due to poor light, keeping in water bottles ${ }^{9}$. The increase in trends of volatile liquid is evident in some other studies of India and Srilanka ${ }^{7}$. According to Rimal HS kerosene poisoning is second highest in eastern Nepal ${ }^{6}$. But in this study kerosene poisoning is the leading cause of poisoning. Our study has similar conclusion as Rathore ${ }^{5}$. It can be explained by regular power cuts in this area for long time which obliges citizens to use kerosene in night.

In chemical poisoning group maximum deaths were due to OP Poisoning. All were suicidal. Other chemicals like cypermethrin, felbamate, fungicide poisonings caused one deaths each.

In the animal bite group snakebite takes the lead consisting $32.4 \%$ of all the incidences. It is higher than previous studies ${ }^{1,10}$. The high incidence can be explained by geographical variation and more numbers of children going to fields to work and thatched kachcha house which is an abode for poisonous snakes like krait. The incidence faces a peak in the July to August due to rainy season. In this time snakes come out of their hole due to seepage of water inside it. This was in agreement with various other works especially done by Matiyahu $\mathrm{L}^{11}$. Scorpion stings are also high in incidence in this season due to swampy weather and habit of floor sleeping in children. Scorpion string consisted $10.1 \%$ of total incidence. Increased incidence of bites \& stings in male children is seen probably because of increased outdoor activity, playing in open fields and going to agricultural fields along with their fathers.

In the drugs group the sedative alprazolam was commonest cause comprising $1.8 \%$ of all incidences. This incidence varies from area to area. In the study by Ghai opioid was one of the leading causes of poisoning ${ }^{10}$. In our area people live remain in joint families where older grandparents use sedatives that could be consumed accidentally by children. Due to restricted use of opioids in Orissa there were no cases of opioid poisoning. Other drugs like anti hypertensives, thyroxine etc were also cause of medications.

Food poisoning after eating in home was most common cause in the food poisoning due to poor storage system and rewarming of food. Mushroom poisoning was a common cause of food poisoning. Intake of unknown mushroom by tribal students in a residential school was the cause. Botulism by consuming stored meat was also a cause of poisoning in four children. A study done by Jan MA from Pakistan stated that mushroom poisoning was a common cause of poisoning in children ${ }^{12}$.

Out of all these admissions 27 children died. The Case Fatality Rate (CFR) in our study was $5.1 \%$. CFR varied in studies done by Rathore and $\mathrm{Ghai}^{5,6,9,10}$. It could be due to types of poisons late presentation to hospitals. 


\section{Conclusion}

Poisoning is a major cause of hospitalisation in paediatric age group. Mostly it is accidental but suicidal causes are rampant in adolescent age group. The incidence of chemical poisonings were significantly high and in increasing trend. Snakebite and scorpion stings

\section{References}

1. World Health Organization. World Health Statistics 2016: Monitoring Health for the SDGs Sustainable Development Goals. World Health Organization; 2016 Jun 8.

2. Kohli U, Kuttiat VS, Lodha R, Kabra SK. Profile of childhood poisoning at a tertiary care centre in North India. Indian J Pediatr 2008;75(8):791-4. DOI: https:// doi.org/10.1007/s12098-008-0105-7

3. Khadgawat R, Garg P, Bansal P, Arya A, Choudhary B. Accidental poisoning. Indian Pediatr 1994;31(12):15557.

4. Gupta S, Govil YC, Misra PK, Nath R, Srivastava $\mathrm{KL}$. Trends in poisoning in children: experience at a large referral teaching hospital. Natl Med J India 1998;11:166-8.

5. Rathore S, Verma AK, Pandey A, Kumar S. Pediatric poisoning trend in Lucknow district, India. J Forensic Res 2013;4(179):2. DOI: 10.4172/2157-7145.1000179 are very common in this area of the world that can be prevented by sleeping on the cots and using mosquito nets. Mortality and morbidity due to paediatric poisonings are preventable hazards. Watchful observation of the child and sharing quality moment with adolescent people will prevent unnecessary casualties.

6. Rwimal HS, Tiwari U, Ghimire K, Thapa M. Hospital Based Study of Poisoning Among Children, 1 to 18 Years of Age in Eastern Nepal. Birat J Health Sci 2017;2(1):138-41.

7. Lucas GN. A hospital based prospective study of acute childhood poisoning. Sri Lanka J Child Health 2006;35:12-9. DOI:http://doi.org/10.4038/sljch.v35i1.3

8. Ganga N, Rajarajeswari G. Poisoning in children. Indian Pediatr 2001;38:208.

9. Mishra S, Ramkumar TV. Effect of 'Cyclone Phailin' on pediatric age group of south Odisha. Int J Recent Sci Res 2014:5(10):1933-5.

10. Ghai OP, Gupta P. Poisonings and accidents. Ghai essential pediatrics. CBS Publishers and distributors. 2004: $6^{\text {th }}$ ed: 640 .

11. Matityahu L, Vladimir G. Acute poisoning in children. Israel Med Assoc J 2000;2:504-6.

12. Jan MA, Siddiqui TS, Ahmed N, Ul-Haq I, Khan Z. Mushroom poisoning in children: clinical presentation and outcome. J Ayub Med Coll Abbottabad 2008;20(2):99-101. 